\title{
Article \\ Novel Multilayer SAW Temperature Sensor for Ultra-High Temperature Environments
}

\author{
Xuhang Zhou $\mathbb{1}$, Qiulin Tan * ${ }^{\mathbb{D}}$, Xiaorui Liang, Baimao Lin, Tao Guo and Yu Gan \\ Science and Technology on Electronic Test and Measurement Laboratory, North University of China, \\ Taiyuan 030051, China; 18434361542@163.com (X.Z.); B1906058@st.nuc.edu.cn (X.L.); \\ linbaimao163@163.com (B.L.); guotao6@nuc.edu.cn (T.G.); ganyu9608@163.com (Y.G.) \\ * Correspondence: tanqiulin@nuc.edu.cn; Tel.: +86-135-9317-7698
}

check for updates

Citation: Zhou, X.; Tan, Q.; Liang, X.; Lin, B.; Guo, T.; Gan, Y. Novel Multilayer SAW Temperature Sensor for Ultra-High Temperature Environments. Micromachines 2021, 12, 643. https://doi.org/ 10.3390/mi12060643

Academic Editor: Klaus Stefan Drese

Received: 8 March 2021

Accepted: 29 March 2021

Published: 31 May 2021

Publisher's Note: MDPI stays neutral with regard to jurisdictional claims in published maps and institutional affiliations.

Copyright: (c) 2021 by the authors. Licensee MDPI, Basel, Switzerland. This article is an open access article distributed under the terms and conditions of the Creative Commons Attribution (CC BY) license (https:// creativecommons.org/licenses/by/ $4.0 /)$.

\begin{abstract}
Performing high-temperature measurements on the rotating parts of aero-engine systems requires wireless passive sensors. Surface acoustic wave (SAW) sensors can measure high temperatures wirelessly, making them ideal for extreme situations where wired sensors are not applicable. This study reports a new SAW temperature sensor based on a langasite (LGS) substrate that can perform measurements in environments with temperatures as high as $1300{ }^{\circ} \mathrm{C}$. The Pt electrode and LGS substrate were protected by an AIN passivation layer deposited via a pulsed laser, thereby improving the crystallization quality of the Pt film, with the function and stability of the SAW device guaranteed at $1100{ }^{\circ} \mathrm{C}$. The linear relationship between the resonant frequency and temperature is verified by various high-temperature radio-frequency (RF) tests. Changes in sample microstructure before and after high-temperature exposure are analyzed using scanning electron microscopy (SEM) and X-ray diffraction (XRD). The analysis confirms that the proposed AlN/Pt/Cr thin-film electrode has great application potential in high-temperature SAW sensors.
\end{abstract}

Keywords: high-temperature electrode; SAW sensor; AlN films; langasite

\section{Introduction}

As science and technology advance, the requirement for functional materials suited to conducting research in ultra-high temperature environments, such as space exploration [1], aero-engine combustion chambers [2-5], geothermal research [6], and nuclear reactors [7], has intensified. Testing measurement systems in high-temperature environments is challenging, with accurate temperature measurements critical to achieve improvements [8]. As common passive wireless devices, surface acoustic wave (SAW) devices have attracted widespread attention because of their high operating frequency, digital compatibility, and high reliability [9-11]. Traditional SAW devices tend to show performance decline or even complete failure in high-temperature environments [12]. Notably, langasite (LGS) piezoelectric single-crystal materials offer unique advantages over traditional piezoelectric materials under such conditions. Compared with $\mathrm{LiNbO}_{3}$ and $\mathrm{LiTaO}_{3}$, LGS has a smaller temperature coefficient and greater stability at high temperatures. Additionally, compared with quartz crystals, LGS has a larger electromechanical coupling coefficient. The melting point of LGS is $1470{ }^{\circ} \mathrm{C}$ and it maintains a stable phase from room temperature up to its melting point, indicating that monocrystalline LGS piezoelectric materials can maintain stable piezoelectric performance at extremely high temperatures. Therefore, the conductive stability of electrodes at high temperatures has become a key factor for determining the suitability of SAW devices, and many researchers have studied the relationship between the conductive performance of metal electrodes at high temperatures and their microstructure. For example, Thompson [13] found that metal films agglomerate at high temperatures, resulting in a loss of electrical conductivity. In addition, Sakharov et al. [14] and Aubert et al. [15,16] prepared Ir-based composite electrodes and demonstrated their stable operation above $800^{\circ} \mathrm{C}$. Alternatively, Moulzolf et al. [17] prepared $\mathrm{Pt}-\mathrm{ZrO}_{2}$ and $\mathrm{Pt}-\mathrm{HfO}_{2}$ composite electrodes that 
operated stably for $4 \mathrm{~h}$ at $1000{ }^{\circ} \mathrm{C}$. In addition, Aubert et al. [18-21] used Ta as the adhesive layer in the electrode to prepare a SAW device capable of stable operation at $1000{ }^{\circ} \mathrm{C}$ for at least $30 \mathrm{~min}$.

In this paper, an AlN passivation layer is deposited on the SAW device to protect the piezoelectric substrate and the interdigital transducer (IDT) electrode, so as to improve the working temperature and working time of the interdigital electrode. This article introduces the design and manufacturing process of this high-temperature SAW sensor, as well as the preparation of the protective film, and the high-temperature experiment performed on the SAW device. A SAW sensor with an interdigital width of $4 \mu \mathrm{m}$ can measure temperatures up to $1300{ }^{\circ} \mathrm{C}$, while having good repeatability and durability at $1100{ }^{\circ} \mathrm{C}$, which is a great improvement.

\section{Materials and Methods}

\subsection{Sensor Fabrication}

In this study, the manufacturing of SAW sensors is divided into two parts: the preparation of interdigital transducers (IDTs) of SAW sensors and the deposition of the protective layer. Typically, SAW resonators have a single-port configuration consisting of an IDT and two reflector sets. Each IDT contains 40 equidistant fingerlike electrodes, with 80 pairs of reflective grids placed on each side of the IDT. The IDTs and reflective fingerlike gratings have a width of $4 \mu \mathrm{m}$. An LGS substrate with an Euler angle $\left(0^{\circ}, 138.5^{\circ}, 15^{\circ}\right)$ was selected, and the IDTs were constructed from $\mathrm{Pt}$, which has a melting point of $1770{ }^{\circ} \mathrm{C}$. Metal $\mathrm{Cr}$ serves as the adhesion layer between Pt and LGS, which increases the adhesion between LGS and Pt and prevents the IDTs from falling off under high temperature. The preparation process of the sensor is shown in Figure 1. The SAW sensor manufacturing process includes substrate cleaning, homogenization, photolithography, and development. The SAW resonator is manufactured using ultraviolet photoengraving (EVG610, EV Group). Additionally, $\mathrm{O}_{2}$ plasma was treated with $60 \mathrm{~W}$ radio-frequency (RF) power for $6 \mathrm{~min}$ (IoN Wave 10, PVA TePla America, Inc., Corona, CA, USA) to increase metal adhesion before deposition. A Cr/Pt $(20 / 200 \mathrm{~nm})$ film was prepared as a fork-finger electrode for the SAW sensor using a magnetron sputtering system.

(a)

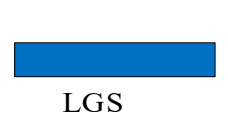

(f)

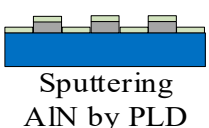

(b)

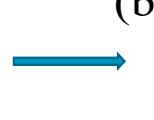

(e)

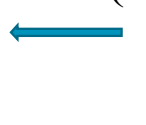

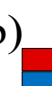

Apply photoresist evenly

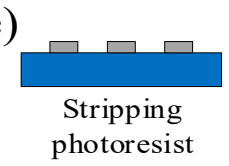

(c)
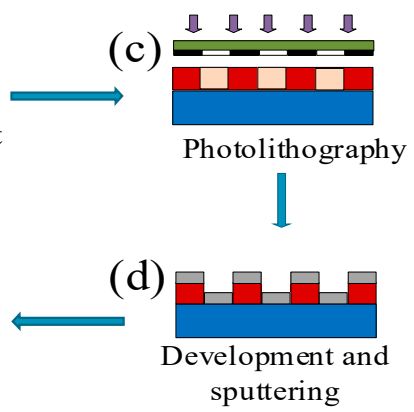

Figure 1. Schematic of the fabrication process of the sensor: (a) clean langasite (LGS) substrate; (b) apply photoresist evenly on the LGS surface; (c) lithography through reticle; (d) deposition of metal Pt/Cr by magnetron sputtering; (e) removal of photoresist; (f) AlN film deposition by PLD.

Next, AlN thin films were deposited on the surfaces of the IDTs and reflective grids to protect the SAW devices. Large electrode pads were exposed to high-temperature testing to connect the Pt wires. A $100 \mathrm{~nm}$-thick AlN layer was deposited on the IDTs and the LGS substrates by pulsed laser deposition (PLD; PLD-450B, Shenyang Scientific Instrument). The laser has a constant voltage output of $22 \mathrm{kV}$, a frequency of $3 \mathrm{~Hz}$, a deposition chamber pressure of $3.5 \times 10^{-4} \mathrm{~Pa}$, and a deposition temperature of $150{ }^{\circ} \mathrm{C}$. The purity of the AlN target was $99.999 \%$.

Before performing measurements, the sample was heated to $700{ }^{\circ} \mathrm{C}$ in a muffle furnace to improve its thermal stability. Thermal annealing not only improves the electrical properties of the $\mathrm{Pt} / \mathrm{Cr}$ electrode at high temperatures, but also eliminates the voids in the AlN 
coating, thus improving the thermal stability of the prepared LGS SAW sensor. Figure 2 shows a schematic diagram of the SAW sensor, a photograph of the prepared sensor, and a schematic diagram of the sensor structure.

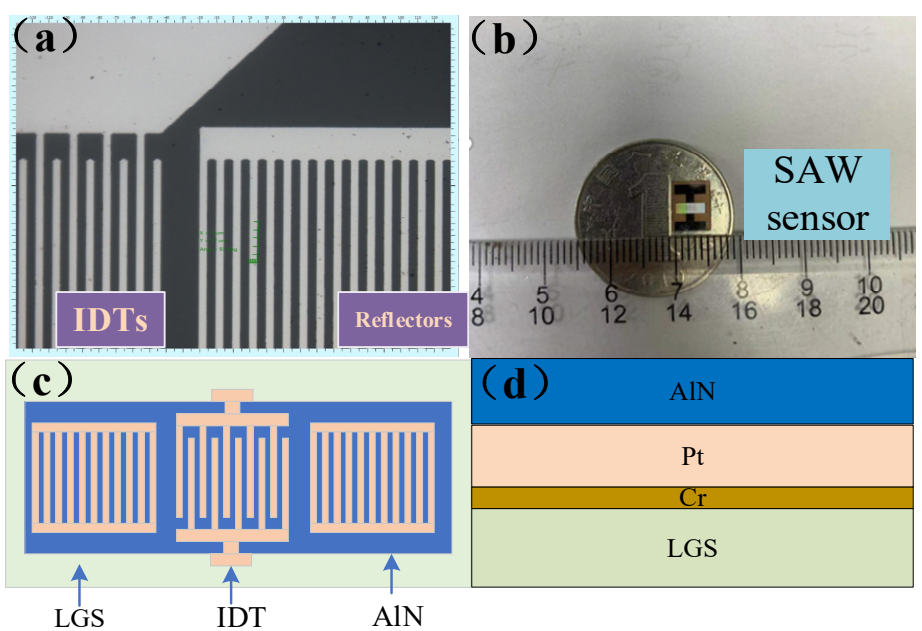

Figure 2. Structure design of surface acoustic wave (SAW) device: (a) the interdigital transducers (IDTs) structure; (b) SAW sensor; (c) diagram of sensor structure; (d) side view of the sensor structure.

\subsection{High-Temperature Measurements}

Figure 3 shows the test scheme for the temperature sensor. The temperature dependence of the resonant frequency of the SAW temperature sensor was measured using an RF network analyzer (E5061B, Agilent) and a muffle furnace. Because the maximum test temperature of the SAW sensor is $1300^{\circ} \mathrm{C}$, it could not be attached to a printed circuit board (PCB). Therefore, the Pt wire was fixed on the fork finger electrode using Pt slurry, while the other end of the Pt wire was connected to the PCB, which, in turn, was connected to the network analyzer via a coaxial cable. When the frequency sweep signal sent by the network analyzer is consistent with the resonant frequency of the sensor, it resonates, and the sensor signals are transmitted back to the network analyzer through the connected $\mathrm{Pt}$ wire. The operating frequency of the sensor was determined by extracting the curve from the network analyzer. The heating rate of the muffle furnace was set at $10^{\circ} \mathrm{C} / \mathrm{min}$, with measurements recorded from $100-1300{ }^{\circ} \mathrm{C}$ in $100{ }^{\circ} \mathrm{C}$ intervals through the K-type thermocouple to obtain more accurate real-time temperature values and the real-time sensor performance.

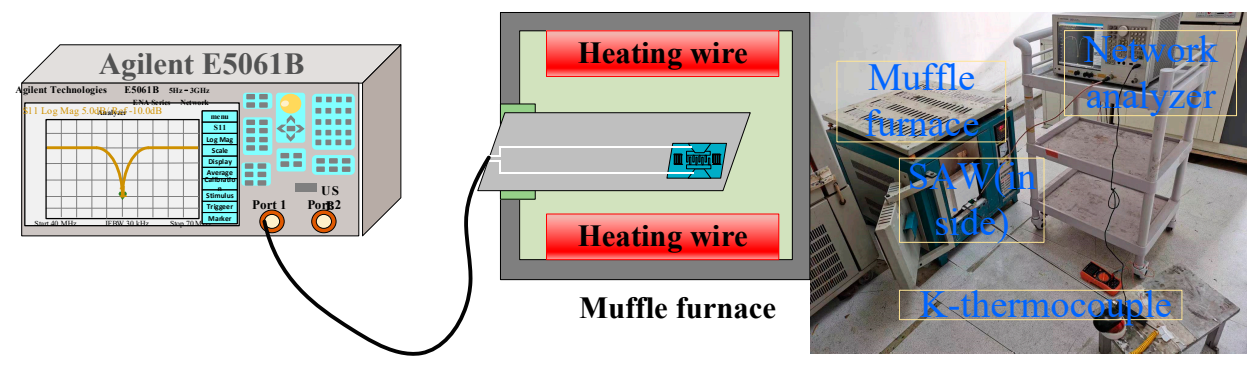

Figure 3. High temperature test system, real-time access to the S11 performance of SAW devices in temperature experiments.

\section{Results and Discussion}

Muffle furnace temperature tests were conducted from $25-1300^{\circ} \mathrm{C}$ using the $\mathrm{S} 11$ curves recorded for different temperature points by the network analyzer. As the experimental temperature continues to rise, the resonant frequency of the sensor continues to decrease, and the sensor can be tested to $1300{ }^{\circ} \mathrm{C}$. When the temperature increases from $25{ }^{\circ} \mathrm{C}$ to $1300{ }^{\circ} \mathrm{C}$, the resonant frequency of the SAW sensor decreases from $158.53 \mathrm{MHz}$ to 
155.59 MHz, and the resonant frequency changes $2.94 \mathrm{MHz}$. In the test temperature range $\left(25-1300{ }^{\circ} \mathrm{C}\right)$, the average change of the sensor's resonance frequency is $2.31 \mathrm{kHz} /{ }^{\circ} \mathrm{C}$.

In addition, the resonance frequency changes nonlinearly as the temperature increases. As shown in Figure 4a, the sensitivity of the sensor gradually increases as the temperature increases. The relationship between sensor frequency and temperature is defined by fitting the experimental response curve. Because LGS has a non-zero frequency temperature coefficient (TCF), the TCF of LGS was close to zero at room temperature and became negative with increasing temperature; therefore, the resonant frequency of the sensor increased and then decreased, including an increase between room temperature and $100{ }^{\circ} \mathrm{C}$. In the low temperature range $\left(100-400{ }^{\circ} \mathrm{C}\right)$, a sensitivity of $0.72 \mathrm{kHz} /{ }^{\circ} \mathrm{C}$ was observed, increasing first to $2.01 \mathrm{kHz} /{ }^{\circ} \mathrm{C}$ for the mid temperature range $\left(400-900{ }^{\circ} \mathrm{C}\right)$, then to $4.38 \mathrm{kHz} /{ }^{\circ} \mathrm{C}$ for the high temperature range $\left(900-1300{ }^{\circ} \mathrm{C}\right)$, as shown in Figure $4 \mathrm{~b}$. To reflect the change in sensitivity, we fitted different curves to the sensor response for different temperature ranges and created a piecewise function to improve the temperature estimation accuracy. The relationship between the resonant frequency and temperature in different temperature ranges is described by Equation (1), where $T$ represents temperature and $F L, F M$, and $F H$ are sensor frequencies in the low, mid, and high temperature ranges, respectively:

$$
\begin{gathered}
F L=-0.000723 T+158.67098\left(100-400{ }^{\circ} \mathrm{C}\right), \\
F M=-0.00201 T+159.14844\left(400-900{ }^{\circ} \mathrm{C}\right), \\
F H=-0.00438 T+161.32726\left(900-1300^{\circ} \mathrm{C}\right) .
\end{gathered}
$$
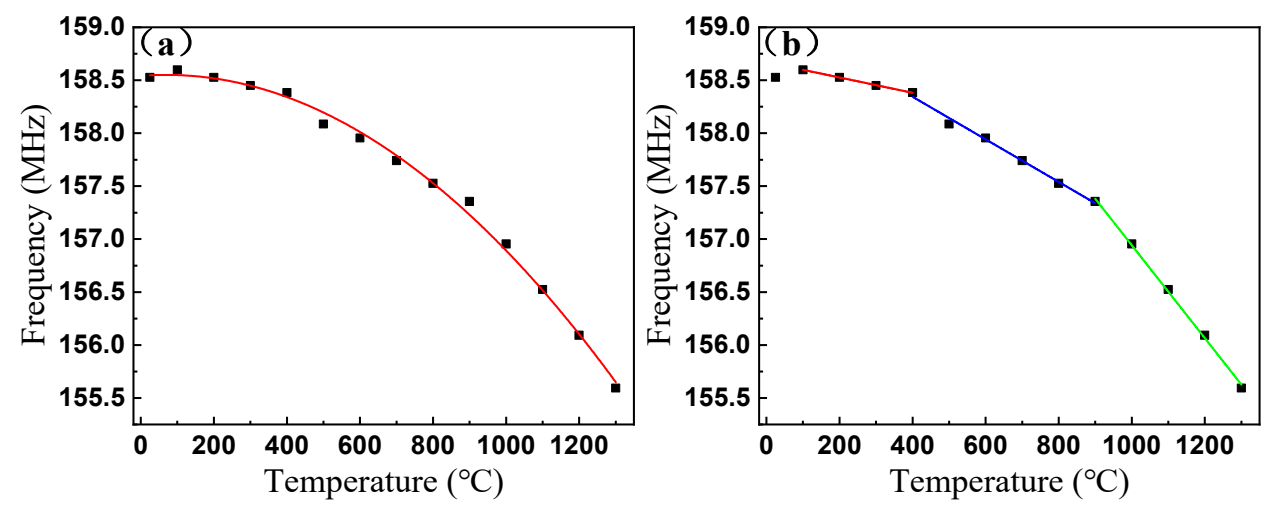

Figure 4. The frequency responsiveness of the SAW sensor during experiment: (a) the frequency responsiveness of the SAW sensor during $1300{ }^{\circ} \mathrm{C}$ experiment; (b) fitting curve for three temperature ranges.

As the temperature increases, the change of the surface temperature of the LGS substrate will cause the elastic constant, piezoelectric constant, and dielectric constant of the substrate to change, thereby changing the speed of the surface acoustic wave propagating on it. The mechanism of the sensor is to influence the change of resonance frequency through the change of LGS surface acoustic wave velocity. In this way, any change in dielectric constant, piezoelectric constant, and elastic constant will affect the change in surface acoustic wave velocity. There are four different cationic lattice points in the LGS crystal structure. As the temperature increases, ions absorb heat energy, thereby increasing their random motion. With temperature changes, this irregular ion movement increases, and the piezoelectric constant and elastic constant change nonlinearly. The dielectric constant of LGS therefore increases with increasing temperature. At different temperatures, the degree of heat-induced molecular motion is different. Higher temperatures increase the thermal motion of molecules and increase the rate of change of dielectric constant. These may be the reasons for different temperature ranges and different sensor sensitivity.

However, the number of times the sensor can be tested at $1300{ }^{\circ} \mathrm{C}$ is limited. When the sensor was tested at $1300{ }^{\circ} \mathrm{C}$ for the fifth time, the resonant frequency of the sensor 
changed abruptly during the cooling process, indicating that the cross-finger electrode of the sensor had broken and raising the possibility of sensor damage. Since the working temperature of most turbine metal alloys does not exceed $950^{\circ} \mathrm{C}$, high temperature sensing in the range of $800^{\circ} \mathrm{C}$ to $1100{ }^{\circ} \mathrm{C}$ is of special significance for the research and development of aeroengines. The sensor was tested three times at $1100{ }^{\circ} \mathrm{C}$ to analyze the stability of the resonant frequency response to temperature changes, as shown in Figure 5a. The repeatability of the sensor response is demonstrated by the consistency of the frequency curves recorded for the three measurement sets. The SAW sensor has been tested at $1100{ }^{\circ} \mathrm{C}$ for $1 \mathrm{~h}$, and the performance of the SAW sensor remains stable, which shows that the SAW sensor has quite good durability.

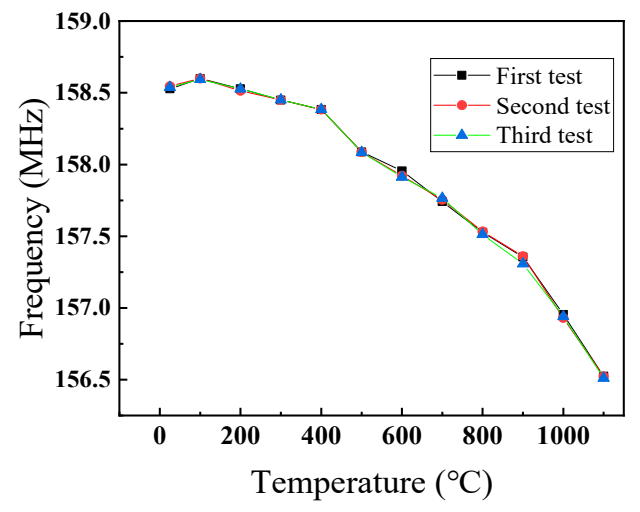

(a)

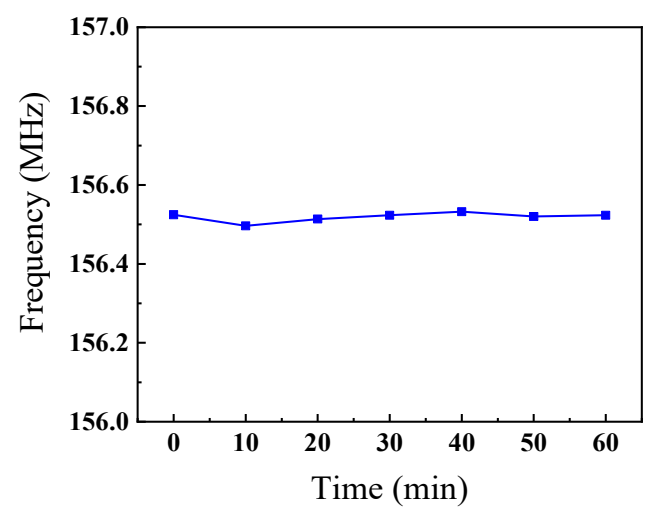

(b)

Figure 5. (a) The three repeatability experiments of extraction points and curves were between frequency and temperature; (b) frequency change graph of heat preservation sensor at $1100{ }^{\circ} \mathrm{C}$.

Figure 6 shows the X-ray diffraction (XRD) results for the AIN/Pt/Cr/LGS samples before and after the high-temperature measurements. Before the measurements were performed, the XRD curve showed no distinct peaks. However, after the high-temperature measurements, a clear peak corresponding to $\mathrm{Pt}$ (111) appeared. There are three possible reasons for this: the $\mathrm{Pt}$ film did not crystallize, the crystallization quality was poor before the high-temperature measurements, or the platinum film crystallized after the high-temperature measurements. The results indicate that the Pt undergoes significant recrystallization when exposed to high temperatures, thus forming completely isolated grains and resulting in a significant increase in resistance, which affects the resonant frequency of the sensor.

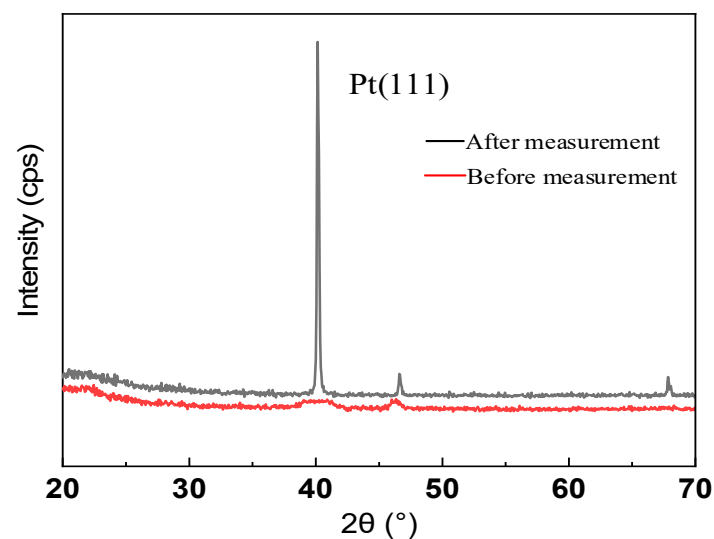

Figure 6. $\theta-2 \theta$ scans of $\mathrm{AlN} / \mathrm{Pt} / \mathrm{Cr} / \mathrm{LGS}$ samples before and after high temperature measurement.

After treatment at high temperature, the adhesion of the $\mathrm{AlN} / \mathrm{Pt} / \mathrm{Cr}$ film to the substrate was very good. After the first high-temperature test at $1300{ }^{\circ} \mathrm{C}$, the frequency 
response did not deteriorate. This result is supported by scanning electron microscopy (SEM). As shown in Figure 7a, before the high temperature measurement, the surface of the sensor is smooth and there are no obvious particles. However, after a high temperature test at $1300{ }^{\circ} \mathrm{C}$, it can be clearly found from Figure $7 \mathrm{~b}, \mathrm{c}$ that there are many small crystal grains on the inter-finger electrode. These small crystal grains are considered to be AlN particles. With stable conductivity, the sensor can continue to work. After the fifth high temperature test at $1300{ }^{\circ} \mathrm{C}$, the surface morphology of the sensor was observed. As shown in Figure 7e,f, some large discontinuous crystal grains appeared on the surface of the sensor. The large crystal grains that appeared at this time originated from the Pt film. Due to the agglomeration and recrystallization of $\mathrm{Pt}$, the interdigital electrode is broken, causing the electrode to lose conductivity and causing damage to the sensor. After testing at $1100^{\circ} \mathrm{C}$, the surface morphology of the sensor is shown in Figure 7d. The surface of the interdigital electrode is relatively smooth, with some small particles and no obvious large particles, which indicates that the sensor is in good condition and can still work continuously.
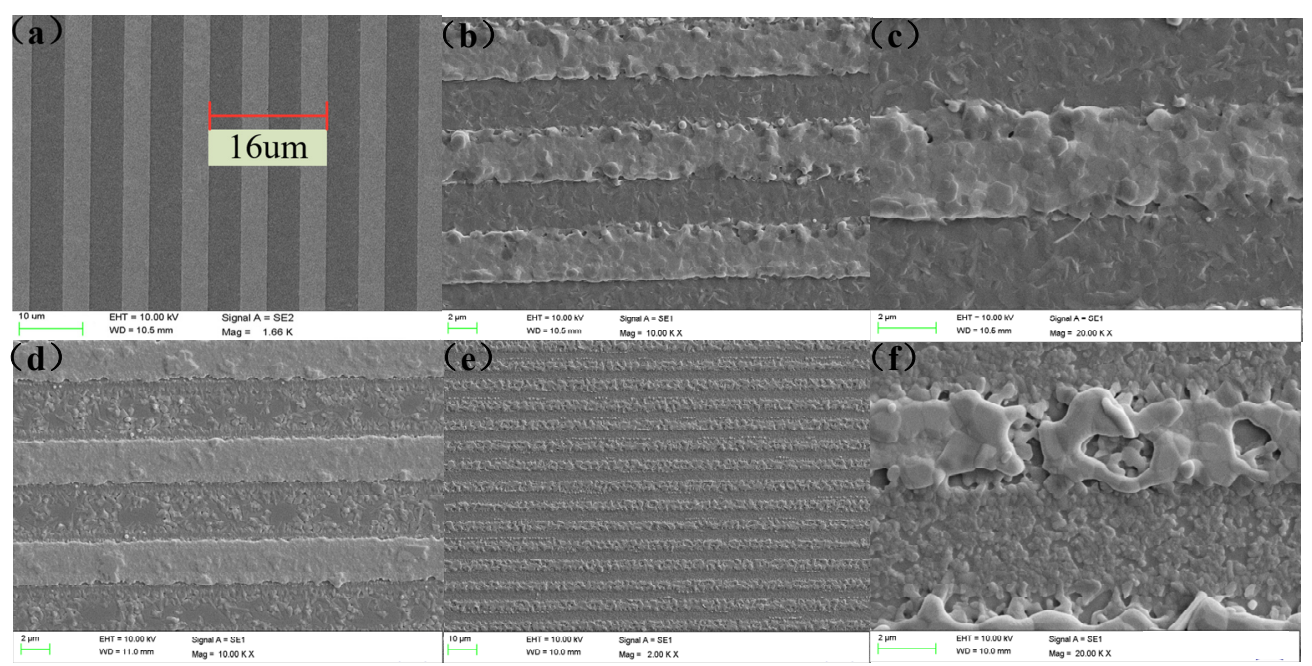

Figure 7. Surface topography of sensor samples: (a) before high temperature measurement; (b) grazing scanning electron microscopy (SEM) image of a AlN/Pt/Cr IDT after the first $1300{ }^{\circ} \mathrm{C}$ high temperature test; (c) partial enlarged view of IDTs; (d) grazing SEM image of AlN/Pt/Cr IDT after annealing at $1100{ }^{\circ} \mathrm{C}$ high temperature test; (e) grazing SEM image of AlN/Pt/Cr IDT after repeated annealing at $1300^{\circ} \mathrm{C}$ high temperature test; and (f) partial enlarged view of IDTs.

Table 1 presents a comparison of the sensor developed in this study with previously reported sensors $[14,17,20]$. The sensor proposed herein has the following advantages:

1. The temperature range is large enough to monitor a relatively large temperature range.

2. The sensor has a long working time at high temperature.

3. Fitting is performed in three temperature stages, which improves the result of sensor estimation.

Table 1. Comparison between the sensors we studied and previously reported sensors.

\begin{tabular}{|c|c|c|}
\hline Electrode Materials & Range & References \\
\hline $\mathrm{Pt} / \mathrm{Ta}$ & $1000{ }^{\circ} \mathrm{C}, 30 \mathrm{~min}$ & [20] \\
\hline Ir & $800^{\circ} \mathrm{C}$ & [14] \\
\hline $\mathrm{Pt}-\mathrm{ZrO}_{2}$ and $\mathrm{Pt}-\mathrm{HfO}_{2}$ & $1000^{\circ} \mathrm{C}$ & [17] \\
\hline Sensor in this study & $1300^{\circ} \mathrm{C} / 1100{ }^{\circ} \mathrm{C}>60 \mathrm{~min}$ & \\
\hline
\end{tabular}

\section{Conclusions}

In this study, an AlN/Pt/Cr SAW temperature sensor was fabricated using microelectromechanical systems (MEMS) technology. The sensor is capable of measuring a 
maximum temperature of $1300^{\circ} \mathrm{C}$, has good repeatability at $1100^{\circ} \mathrm{C}$ and a high temperature endurance of not less than $1 \mathrm{~h}$, and is approved for passivating protection of AlN thinfilm covered LGS substrates and IDTs of SAW devices. The resonant frequency of the sensor drifts by $2.94 \mathrm{MHz}$ over the observed temperature range. To improve the precision of the sensor estimation results, the temperature dependency of the sensor response from $25-1300{ }^{\circ} \mathrm{C}$ was divided into three parts, each with a different linear relationship between the temperature and the resonant frequency. As research progresses, remote wireless passive high-temperature testing will be realized by attaching the SAW sensor to a ceramic plate and bonding the helical antenna with Pt paste. The real-time operating temperature of turbine blades in high temperature and harsh environments can be directly measured by LGS-based wireless passive sensors. By continuously optimizing the size of the antenna, smaller size wireless transmission can be achieved. At the same time, for higher temperatures, new piezoelectric material SAW sensors need to be considered. Our method can be a good reference point to construct new devices.

Author Contributions: Methodology and writing, X.Z.; conceptualization, Q.T.; formal analysis, X.L.; writing-review and editing. B.L.; investigation, T.G.; software, Y.G. All authors have read and agreed to the published version of the manuscript.

Funding: This work was supported by National Natural Science Foundation of China (Grant No. U1837209), the Outstanding Young Talents Support Plan of Shanxi province, the Young Sanjin Scholar Distinguished Professor Plan of Shanxi Province, the Innovative Research Group Project of National Natural Science Foundation of China (Grant No. 51821003), and the Shanxi"1331 project" keys subjects Construction, and in part by National Key R\&D Program of China (Grant No. 2018YFB2003103).

Conflicts of Interest: The authors declare no conflict of interest.

\section{References}

1. Jurgens, R.F. High-temperature electronics applications in space exploration. IEEE Trans. Ind. Electron. 1982, IE-29, 107-111. [CrossRef]

2. Fonseca, M.A.; English, J.M.; von Arx, M.; Allen, M.G. Wireless micromachined ceramic pressure sensor for hightemperatureapplications. J. Microelectromech. Syst. 2002, 11, 337-343. [CrossRef]

3. Korashy, A.; Attia, H.; Thomson, V.; Oskooei, S. Characterization of fretting wear of cobalt-based superalloys at high temperature for aero-engine combustor components. Wear 2015, 330-331, 327-337. [CrossRef]

4. Li, Y.; Yu, Y.; San, H.; Wang, Y.; An, L. Wireless passive polymerderived SiCN ceramic sensor with integrated resonator/antenna. Appl. Phys. Lett. 2013, 103, 163505. [CrossRef]

5. Gregory, O.J.; Conkle, J.R.; Birnbaum, T.J. Wireless Temperature Measurement System and Methods of Making and Using Same. U.S. Patent 8348504 B2, 8 January 2013.

6. Schmitt, A.K.; Hulen, J.B. Buried rhyolites within the active, hightemperature Salton Sea geothermal system. J. Volcanol. Geotherm. Res. 2008, 178, 708-718. [CrossRef]

7. Fernandez, A.F.; Gusarov, A.I.; Brichard, B.; Bodart, S.; Lammens, K.; Berghmans, F.; Decreton, M.C.; Megret, P.; Blondel, M.; Delchambre, A. Temperature monitoring of nuclear reactor cores with multiplexed fiber Bragg grating sensors. Opt. Eng. 2002, 41, 1246-1255.

8. Zhao, R.; Shao, G.; Cao, Y.; An, L.; Xu, C. Temperature sensormade of polymer-derived ceramics for high-temperature applications. Sens. Actuators A Phys. 2014, 219, 58-64. [CrossRef]

9. Kang, A.; Zhang, C.R.; Jia, X.J.; Han, T.; Li, R.; Li, X. SAW-RFID enabled temperature sensor. Sens. Actuators A Phys. 2013, 201, 105-113. [CrossRef]

10. Rodriguez-Madrid, J.G.; Iriarte, G.F.; Williamsb, O.A.; Calle, F. High precision pressure sensors based on SAW devices in the GHz range. Sens. Actuators A 2013, 189, 364-369. [CrossRef]

11. Shu, L.; Peng, B.; Yang, Z.; Wang, R.; Deng, S.; Liu, X. High-temperature SAW wireless strain sensor with langasite. Sensors 2015, 15, 28531-28542. [CrossRef] [PubMed]

12. Mrosk, J.W.; Berger, L.; Ettl, C.; Fecht, H.J.; Fischerauer, G.; Dommann, A. Materials issues of SAW sensors for high-temperature applications. IEEE Trans. Ind. Electron. 2001, 48, 258-264. [CrossRef]

13. Thompson, C.V. Solid-state dewetting of thin films. Annu. Rev. Mater. Res. 2012, 42, 399-434. [CrossRef]

14. Sakharov, S.; Zabelin, A.; Medvedev, A.; Buzanov, O.; Kondratiev, S.; Roshchupkin, D.; Shvetsov, A.; Zhgoon, S. Technological Process and Resonator Design Optimization of Ir/LGS HighTemperature SAW Devices. In Proceedings of the 2014 IEEE International Ultrasonics Symposium Proceedings, Chicago, IL, USA, 3-6 September 2014; pp. 1632-1635. 
15. Aubert, T.; Elmazria, O.; Bardong, J.; Bruckner, G. Iridium Interdigital Transducers for Ultra-high-temperature SAW Devices. In Proceedings of the IEEE International Ultrasonics Symposium Proceedings, Orlando, FL, USA, 18-21 October 2011; pp. 2065-2068.

16. Taguett, A.; Aubert, T.; Lomello, M.; Legrani, O.; Elmazria, O.; Ghanbaja, J.; Talbi, A. Ir-Rh thin films as high-temperature electrodes for surface acousticwave sensor applications. Sens. Actuators A 2016, 243, 35-42. [CrossRef]

17. Moulzol, S.C.; Frankel, D.J.; Pereira Da Cunha, M.; Lad, R.J. Electrically conductive Pt-Rh/ZrO2 and Pt-Rh/HfO2 nanocomposite electrodes for high temperature harsh environment sensors. Proc. SPIE 2013, 8763, 87630F.

18. Aubert, T.; Elmazria, O.; Assouar, B.; Bouvot, L.; Oudich, M. Surface acoustic wave devices based on AlN/sapphire structure for high temperature applications. Appl. Phys. Lett. 2010, 96, 203503. [CrossRef]

19. Aubert, T.; Elmazria, O.; Assouar, B.; Bouvot, L.; Hehn, M.; Weber, S.; Oudich, M.; Genève, D. Behavior of platinum/tantalum as interdigital transducers for SAW devices in high-temperature environments. IEEE Trans. Ultrason. Ferroelectr. Freq. Control 2011, 58, 603-610. [CrossRef] [PubMed]

20. Aubert, T.; Elmazria, O.; Assouar, B.; Blampain, E.; Hamdan, A.; Geneve, D.; Weber, S. Investigations on AlN/Sapphire piezoelectric bilayer structure for high-temperature SAW applications. IEEE Trans. Ultrason. Ferroelectr. Freq. Control 2012, 59, 999-1005. [CrossRef] [PubMed]

21. Elmazria, O.; Aubert, T. Wireless SAW sensor for high temperature applications: Material point of view. Proc. SPIE 2011, 8066,806602 . 